\title{
Shear connection requirements for composite cellular beams
}

\author{
E. S. Aggelopoulos ${ }^{a *}$, F. Hanus ${ }^{\mathrm{b}}$ and R.M. Lawson ${ }^{\mathrm{a}, \mathrm{c}}$ \\ ${ }^{a}$ The Steel Construction Institute (SCI), UK \\ ${ }^{\mathrm{b}}$ ArcelorMittal R\&D, Luxembourg \\ 'Department of Civil and Environmental Engineering, University of Surrey, UK \\ *corresponding author, e-mail address: e.aggelopoulos@steel-sci.com
}

\begin{abstract}
Beams with regular circular web openings (cellular beams) are often used in composite construction. Rules for the minimum degree of shear connection in composite beams are presented in Eurocode 4 but were derived for solid web beams in propped construction. This paper investigates the degree of shear connection requirements for composite cellular beams, focusing on the combined effect of using a steel section with regularly spaced, large circular web openings and unpropped construction conditions. The effect of the diameter and the spacing of the openings is also investigated.

In order to provide rules for the minimum degree of shear connection in cellular beams, parametric finite element (FE) analyses were carried out for beams in the span range of 9 to $18 \mathrm{~m}$. The results were calibrated against a $15.3 \mathrm{~m}$ span composite cellular beam test with a low degree of shear connection. The proposed minimum degree of shear connection requirements for beams with regular circular web openings are presented for both propped and unpropped construction, and for symmetric and asymmetric steel sections. Comparisons are made with equivalent beams with solid webs (no openings) and it is shown that significant relaxation in the codified minimum degree of shear connection to the current version of Eurocode 4 can be justified for composite cellular beams.
\end{abstract}

Keywords: Beams \& girders; Buildings, Structures \& design; Codes of practice \& standards; Composite structures.

\section{Introduction}

Cellular beams offer the advantage of being able to pass service ducts and equipment through the web openings (Fig. 1). Cellular beams are often designed as composite beams for increased stiffness and bending resistance. Generally, they are designed to act compositely with composite slabs (i.e. using profiled steel decks) through the use of headed stud shear connectors. The design of composite beams with large web openings is covered in [1], and it will be explicitly covered by the next version of EN 1994-1-1 [2], which is anticipated to be completed by 2020 .

Composite beams are generally designed for partial shear interaction, which means that the combined resistance of the shear connectors is less than the smaller of the compressive resistance of the concrete flange and the tensile resistance of the steel section. The current EN 1994-1-1 rules define a minimum degree of shear connection depending on parameters such as the steel grade, the beam span and the level of asymmetry $\left(\mathrm{A}_{\mathrm{fb}} / \mathrm{A}_{\mathrm{ft}}\right)$. The minimum degree of shear connection formulae were developed in the 1990s for beams with solid webs that are propped in construction (all loads supported by the composite section).

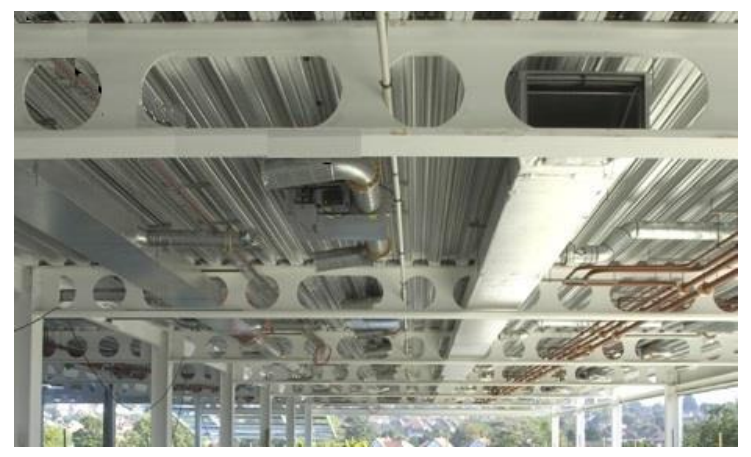

Fig. 1. Cellular beams with regular openings. 
Currently, many composite designs cannot achieve the codified degree of shear connection demands, since it is not possible to place a sufficient number of shear connectors along the beam span as dictated by the wide spacing of the deck ribs. However, the behaviour of unpropped beams and cellular beams in particular allows the use of lower shear connection requirements, which are not accounted for in Codes. In the case of cellular beams, it is not necessary to develop plasticity in the 'missing' web which means that both the flange strains and the end slip are lower than in solid web beams. For unpropped beams, the self-weight acts on the steel section alone. The combined effect for un-propped cellular beams is very important and leads to designs being acceptable that otherwise were not permitted by the current Eurocode 4 rules.

In order to provide rules for the minimum degree of shear connection in propped and unpropped cellular beams, parametric finite element (FE) analyses were carried out using the generalised FE packages ANSYS and Abaqus for composite beams in the span range of 9 to $18 \mathrm{~m}$. The parameters investigated included the form of construction (propped and unpropped), the beam span and the ratio of the flange areas. Comparisons were made of cellular beams with various opening diameters against beams with solid webs.

The results were calibrated against a $15.3 \mathrm{~m}$ span composite cellular beam test with 2.4:1 bottom:top flange asymmetry and 37\% degree of shear connection, which is significantly less than the $88 \%$ degree of shear connection required by Eurocode 4.

The proposed minimum degree of shear connection requirements for beams with regular circular web openings are presented for both propped and unpropped construction and for symmetric and asymmetric steel sections. A comparison is made with equivalent beams with solid webs (no openings) and the current shear connection rules, and modification factors for the minimum degree of shear connection in cellular beams are proposed.

\section{FE models description and validation}

Two independent parametric FE models were developed in ANSYS and Abaqus. The steel section was modelled using 2D shell elements in ANSYS and 3D solid elements in Abaqus. Solid elements were used for modelling the slab. In order to increase computational efficiency, modelling of the shear connection was simplified through the use of nonlinear springs between the slab and the steel section. This simplification was effectively used by other researchers (e.g. [3]), but requires that the forceslip characteristics of the shear connectors are known. The force-slip characteristics in this case were available from a large number of push-out tests [4].

Steel was modelled assuming a bilinear stress-strain relationship and included strain hardening $\left(\mathrm{E}_{\mathrm{s}} / 100\right.$ assumed gradient). The concrete was modelled in ANSYS assuming a trilinear material model in an attempt to replicate the Eurocode 2 [5] recto-parabolic stress-strain relationship. However, no unloading was included for strains exceeding the limiting value of 0.002 . For the range of analyses carried out in ANSYS (low degrees of shear connection and flange asymmetry up to $1.6: 1)$, the concrete strain was not expected to exceed this value, which was verified by monitoring of the strain in the FE results. In the Abaqus model, the nonlinear concrete material law from EN 19921-1 and Concrete Damage Plasticity Model capability in the software were used.

For the unpropped case, a methodology was followed where the analyses are carried out in steps in order to accurately model the loading stages. Therefore, the self-weight of the composite beam was applied to the steel section alone by assigning an existing stress field to the section (i.e. a prestressed condition).

The FE models were validated against a $15.3 \mathrm{~m}$ span cellular composite beam test [6]. The test setup simulated unpropped construction conditions. The properties assumed in the analyses for the shear connectors were representative of load-slip data obtained from push-out tests on a similar slab configuration. The properties of concrete and steel were also obtained by cube tests and tensile tests, respectively.

The results from the analysis of the $15.3 \mathrm{~m}$ span composite cellular beam test are presented in Fig. 2 in which the load versus deflection and load versus end slip graphs obtained from the models and the test are shown. Overall good agreement between the FE results and the test is observed. The value of the imposed load (excluding the self-weight of the beam) corresponding to the attainment of the 
theoretical plastic resistance moment for the test beam (calculated using measured material properties) is also given in Fig. 2, and this was reached in the test. As shown, several loading and unloading cycles were applied in the actual test, progressively increasing the magnitude of the load (given as multiples of a working load of $5 \mathrm{kN} / \mathrm{m}^{2}$ ). It should also be noted that the test slip plotted in Fig. 2 is the average between the two sides of the span.
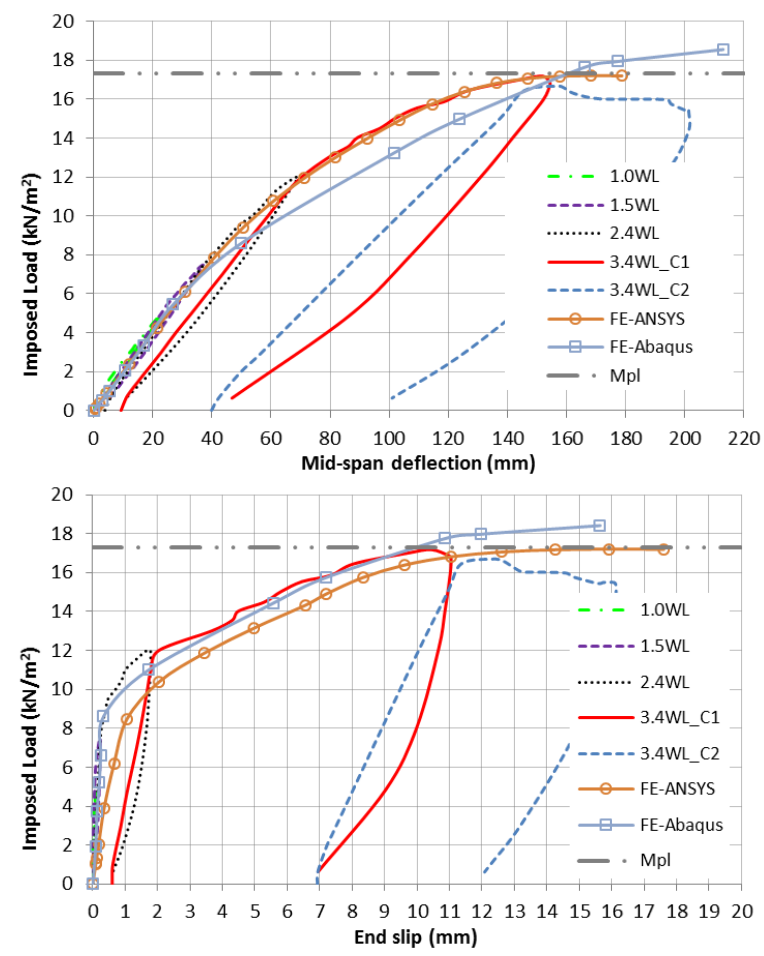

Fig. 2. Load-deflection (top) and load-slip (bottom) plots obtained from the numerical analyses and the beam test.

\section{Methodology and parameters investigated}

\subsection{Parametric study description}

A range of parameters was investigated; the beam span, the diameter of the web openings, the construction conditions (propped or unpropped) and the asymmetry in the flange areas of the steel section. Comparisons were made to the current EN 1994-1-1 shear connection requirements for symmetric and asymmetric composite beams with equivalent solid web sections.

The symmetric cases were the basis for all the analyses carried out using ANSYS. Three spans were considered, $9 \mathrm{~m}, 12 \mathrm{~m}$ and $15 \mathrm{~m}$. The steel section sizes chosen were IPE400, IPE500 and IPE600, respectively, and are representative sections for these spans (span to depth ratio of
22.5 to 25). The slab was chosen as $150 \mathrm{~mm}$ deep with an $80 \mathrm{~mm}$ deep decking. The steel grade was S355 $\left(\mathrm{f}_{\mathrm{y}}=355 \mathrm{~N} / \mathrm{mm}^{2}\right)$ and the concrete compressive strength was $30 \mathrm{~N} / \mathrm{mm}^{2}$.

The width of the concrete flange was taken as the effective width of beam span/4. For the cellular beam cases, the diameter of the opening $\mathrm{h}_{\mathrm{o}}$ was $250 \mathrm{~mm}, 325 \mathrm{~mm}$ and $375 \mathrm{~mm}$ depending on the steel section size $\left(\mathrm{h}_{\mathrm{o}} \mathrm{h}_{\text {web }}\right.$ between 0.67 and 0.69 ). The spacing of the openings, $s$, was kept constant at $1.6 \mathrm{~h}_{\mathrm{o}}$, which is typical of composite cellular beams.

The details of the asymmetric cellular cases modelled in ANSYS are summarised in Table 1. For the asymmetric solid web cases, the area of the bottom tee was increased in accordance with the information given in Table 1. Design checks were carried out to ensure the practicability of all the cases selected (so that the beams satisfied the ultimate and serviceability limit states requirements for the span and typical office loading conditions).

Table 1.Asymmetric cellular composite beam cases modelled in ANSYS.

\begin{tabular}{ccccccc}
\hline $\begin{array}{c}\mathbf{L} \\
{[\mathbf{m}]}\end{array}$ & $\begin{array}{c}\text { Top } \\
\text { tee }\end{array}$ & $\begin{array}{c}\text { Bot. } \\
\text { tee }\end{array}$ & $\begin{array}{c}\mathbf{A}_{\mathbf{f t}} / \\
\mathbf{A}_{\mathbf{f t}}\end{array}$ & $\begin{array}{c}\mathbf{h}_{\mathbf{o}} \\
{[\mathbf{m m}]}\end{array}$ & $\begin{array}{c}\mathbf{s} \\
{[\mathbf{m m}]}\end{array}$ & $\begin{array}{c}\mathbf{h} \\
{[\mathbf{m m}]}\end{array}$ \\
\hline 9 & IPE & IPE & 1.5 & 250 & 400 & 400 \\
& 400 & 550 & & & & \\
12 & IPE & IPE & 1.6 & 325 & 520 & 500 \\
& 500 & 750 & & & & \\
15 & IPE & IPE & 1.5 & 375 & 600 & 600 \\
& 600 & 750 & & & & \\
\hline
\end{tabular}

For the cases with higher flange asymmetry modelled in Abaqus, the geometries of the asymmetric steel beams were chosen on the basis of satisfying ULS and SLS requirements for typical office building loads. Both IPE/HEA and HEA/HEB steel section combinations were considered, which gave relatively high asymmetries up to $2.3: 1$.

The configurations considered are listed in Table 2 with their geometrical data. Configurations 1 and 2 relate to different types of decking, i.e. $60 \mathrm{~mm}$ and $80 \mathrm{~mm}$ deep profiles, respectively. The configurations shown were investigated assuming either one or two studs per rib. The same cases were repeated for solid web cases and for propped and unpropped construction conditions. In all cases, the orientation of the deck ribs was transverse to the beam axis. 
Table 2.Asymmetric cellular composite beam configurations modelled in Abaqus.

\begin{tabular}{|c|c|c|c|c|c|c|}
\hline $\begin{array}{c}\mathbf{L} \\
{[\mathbf{m}]}\end{array}$ & $\begin{array}{c}\text { Top } \\
\text { tee }\end{array}$ & $\begin{array}{c}\text { Bot. } \\
\text { tee }\end{array}$ & $\begin{array}{l}\mathbf{A}_{\mathrm{fb}} / \\
\mathbf{A}_{\mathbf{f t}}\end{array}$ & $\begin{array}{c}\mathbf{h}_{\mathbf{o}} \\
{[\mathbf{m m}]}\end{array}$ & $\begin{array}{c}1 \text { or } \\
2^{*}\end{array}$ & $\begin{array}{c}\mathbf{h} \\
{[\mathbf{m m}]}\end{array}$ \\
\hline 10 & $\begin{array}{l}\text { IPE } \\
330\end{array}$ & $\begin{array}{c}\text { HEA } \\
300\end{array}$ & 2.3 & 280 & 1 & 422 \\
\hline 12 & $\begin{array}{l}\text { IPE } \\
360\end{array}$ & $\begin{array}{c}\text { HEA } \\
340\end{array}$ & 2.3 & 310 & 1 & 470 \\
\hline 15 & $\begin{array}{l}\text { IPE } \\
450\end{array}$ & $\begin{array}{c}\text { HEA } \\
450\end{array}$ & 2.3 & 350 & 1 & 537 \\
\hline 15 & $\begin{array}{c}\text { HEA } \\
360\end{array}$ & $\begin{array}{c}\text { HEB } \\
360\end{array}$ & 1.3 & 320 & 1 & 484 \\
\hline 12 & $\begin{array}{l}\text { IPE } \\
450\end{array}$ & $\begin{array}{c}\text { HEA } \\
450\end{array}$ & 2.3 & 400 & 2 & 609 \\
\hline 15 & $\begin{array}{l}\text { IPE } \\
500\end{array}$ & $\begin{array}{c}\text { HEA } \\
550\end{array}$ & 2.3 & 480 & 2 & 719 \\
\hline 18 & $\begin{array}{l}\text { IPE } \\
600\end{array}$ & $\begin{array}{c}\text { HEA } \\
800\end{array}$ & 2.0 & 640 & 2 & 989 \\
\hline 15 & $\begin{array}{c}\text { HEA } \\
450\end{array}$ & $\begin{array}{c}\text { HEB } \\
450\end{array}$ & 1.2 & 410 & 2 & 613 \\
\hline $\begin{array}{l}{ }^{1} \mathrm{~h}_{\mathrm{p}} \\
130 \\
{ }^{1} \mathrm{~h}_{\mathrm{p}} \\
150\end{array}$ & $\begin{array}{l}60 \mathrm{~mm} \\
\mathrm{n} \\
80 \mathrm{~mm}\end{array}$ & $d_{\text {stud }}=$ & & $h_{\text {sc }}=$ & & $\begin{array}{l}\mathrm{h}_{\mathrm{s}}= \\
\mathrm{h}_{\mathrm{s}}=\end{array}$ \\
\hline
\end{tabular}

\subsection{Determination of critical degree of shear connection}

The degree of shear connection was determined and compared against the minimum degree of shear connection required by EN 1994-1-1. For all the configurations considered, the EN 1994-1-1 criteria were only met for one configuration.

The procedure followed was the same as that used for the calibration of the shear connection rules of EN 1994-1-1 [7]. The degree of shear connection required to limit slip in the shear connectors to $6 \mathrm{~mm}$ was determined for an applied load that was within $5 \%$ of the theoretical plastic bending resistance of the beam for the particular degree of shear connection. Therefore, the slip for various degrees of shear connection was calculated at a level of load corresponding to (the attainment of) $95 \%$ of the plastic resistance moment $\left(\mathrm{M}_{\mathrm{pl}}\right)$ of the beam. The degree of shear connection that gave a slip no greater than $6 \mathrm{~mm}$ was recorded.

The calculation of the plastic resistance moment of the composite beams was determined from plastic stress-block method of analysis and accounted for the degree of shear connection in each case. For cellular beams, in particular, the calculation was performed at the centre of an opening.

\subsection{Effect of circular web openings}

The effect of the regular circular web openings and their size on the shear connection requirements was studied to determine the range of applicability of the current findings. The typical case of $12 \mathrm{~m}$ span with a symmetric section (IPE500) was used for this purpose. Three analyses were carried out, one without web openings and two with the diameter of the circular opening being taken as 0.6 or 0.8 times the depth of the web, which are typically the limits of the practical application range.

Comparing the cases with and without web openings, it is clear that there is scope for relaxing the shear connection requirements for cellular beams with regular circular openings. The minimum required degree of shear connection for the beam with the solid web (12 m span, propped, symmetric, S355 steel grade) is $61 \%$ according to EN 1994-1-1. This was verified in the FE for the equivalent case, where, for a degree of shear connection equal to $59 \%$, the slip was just over $5 \mathrm{~mm}$ at a moment of $0.95 \mathrm{M}_{\mathrm{pl}}$. This shows good agreement for solidweb propped beams.

For the cases with regular web openings of diameter 0.6 to 0.8 times the depth of the web, the required degree of shear connection was found to be considerably lower. Even when the size/diameter of the web opening is the smallest of the selected range, the slip was approximately $5 \mathrm{~mm}$ for a significantly lower degree of shear connection (39\%). When the degree of shear connection was further reduced to $34 \%$, the analysis failed to reach $0.95 \mathrm{M}_{\mathrm{pl}}$ for this case.

The results from these analyses indicate there is some dependency of the minimum shear connection on the diameter of the opening. For the case where the diameter of the opening was 0.8 times the web depth, different results were obtained (i.e. slip was less than $6 \mathrm{~mm}$ for a degree of shear connection of approximately $30 \%$ ). However, for the intermediate case where the depth was approximately 0.7 times the web depth, the results were no different to the case with a larger opening. These results suggest that, in addition to having circular openings placed regularly along the span of the beam, rather than isolated openings, the size of the opening should be greater than $60 \%$ of the beam web depth for the modified shear connection requirements presented in this paper to apply. 


\section{Results}

\subsection{Comparison between cellular beams and beams with solid webs}

The differences in the response of a solid web composite beam and a cellular composite beam with respect to the shear connection requirements at a moment equal to $0.95 \mathrm{M}_{\mathrm{pl}}$ are discussed. The $12 \mathrm{~m}$ span propped case with an asymmetry in the flange areas of 1.6 was chosen for this purpose. This level of asymmetry is commonly used for cellular beams in composite construction and therefore is considered to be representative.

The load vs deflection and load vs slip responses for the solid web beam and the cellular beam are shown in Fig. 3 and Fig. 4, respectively. The degree of shear connection for the solid web beam was $74 \%$, while for the cellular beam it was only $48 \%$.

At the reference moment of $0.95 \mathrm{M}_{\mathrm{pl}}$, the slip in the solid web beam was approximately $6.2 \mathrm{~mm}$ which is very close to the slip capacity of the shear connectors assumed in EN 1994-11. The degree of shear connection required by EN 1994-1-1 for this beam is 69\%, and therefore the codified requirements are essentially verified in this instance. The deflection at a moment of $0.95 \mathrm{M}_{\mathrm{pl}}$ was slightly higher than span/100.

At the reference moment of $0.95 \mathrm{M}_{\mathrm{pl}}$, the slip in the shear connectors for the beam with the openings was approximately $5.9 \mathrm{~mm}$, which is close to the slip capacity assumed in EN 1994-11. The deflection was close to span/130 at this point. The degree of shear connection required by the current EN 1994-1-1 for this beam would also be $69 \%$, but the FE results suggest that the degree of shear connection could be significantly lower than this value.

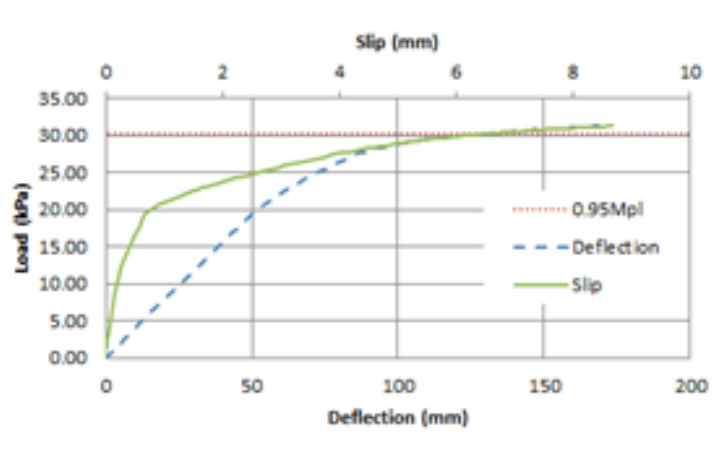

Fig. 3. Load vs deflection and load vs slip plots for the $12 \mathrm{~m}$ span solid web beam $\left(\mathrm{A}_{\mathrm{fb}} / \mathrm{A}_{\mathrm{ft}}=1.6\right)$ and $74 \%$ shear connection.

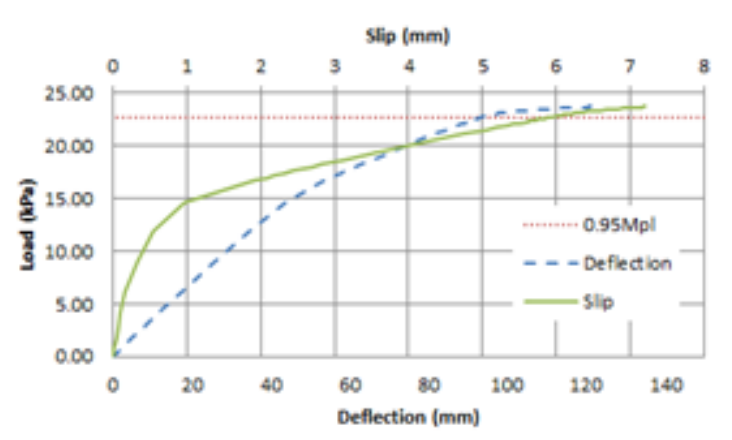

Fig. 4. Load vs deflection and load vs slip plots for the $12 \mathrm{~m}$ span cellular beam

$\left(\mathrm{A}_{\mathrm{fb}} / \mathrm{A}_{\mathrm{ft}}=1.6\right)$ and $48 \%$ shear connection.

\subsection{Shear connection requirements for cellular composite beams}

It is proposed that the degree of shear connection for cellular composite beams can be determined from the following relationships:

1. For cellular beams that are propped in construction, it is proposed that the degree of shear connection to Eurocode 4 is modified by the factor, as shown below:

$$
\eta=\eta_{E C 4}\left(1-\frac{0.7 h_{0}}{h} \frac{A_{f t}}{A_{f b}}\right) \leq 1 \text {, but } \eta \geq 0.4
$$

where $\eta_{E C 4}$ refers to the relevant minimum degree of shear connection for solid web beams in EN 1994-1-1, as follows:

$$
\eta_{E C 4}=1-\left(\frac{355}{f_{y}}\right)(0.75-0.03 L) \text {. }
$$

2. For cellular beams that are unpropped in construction, an additional factor is introduced to take account of the loads applied to the steel section, as shown below:

$\eta=\eta_{E C 4}\left(1-\frac{M_{s w}}{M_{p l}}\right)\left(1-\frac{0.7 h_{0}}{h} \frac{A_{f t}}{A_{f b}}\right) \leq 1$, but $\eta \geq 0.3$

where $M_{s w} / M_{p l}$ is the ratio of the unfactored self-weight bending moment acting on the steel beam at the construction stage to the plastic resistance moment for the degree of shear connection of the composite beam.

A summary of the analyses results in terms of the minimum degree of shear connection from Abaqus is given in Fig. 5. The results from ANSYS are also presented in Fig. 6 and Fig. 7. The results compare the current EN 1994-1-1 shear connection requirements against the $\mathrm{FE}$ 
results for cellular beams and beams with solid webs, as well as the proposed modifications to the current requirements presented in Eqs. (1) and (2).

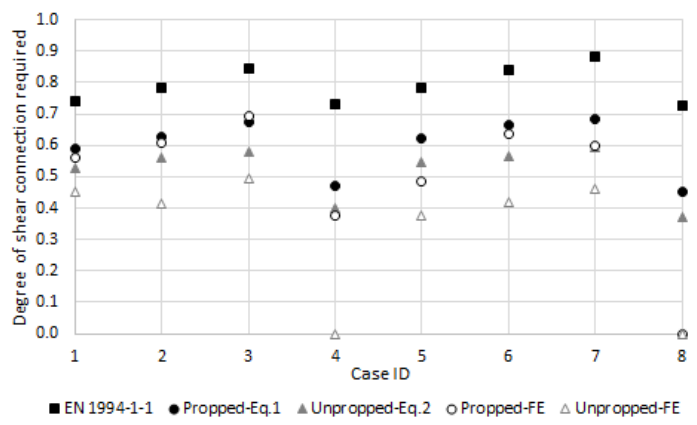

Fig. 5. Minimum degree of shear connection for cellular beams analysed in Abaqus.

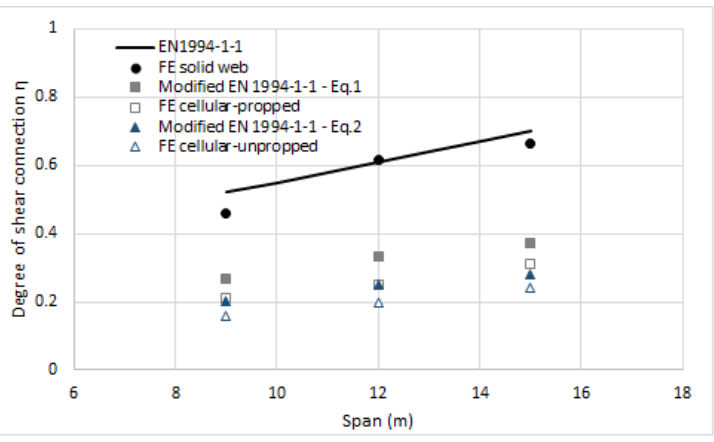

Fig. 6. ANSYS results for symmetric cellular beams.

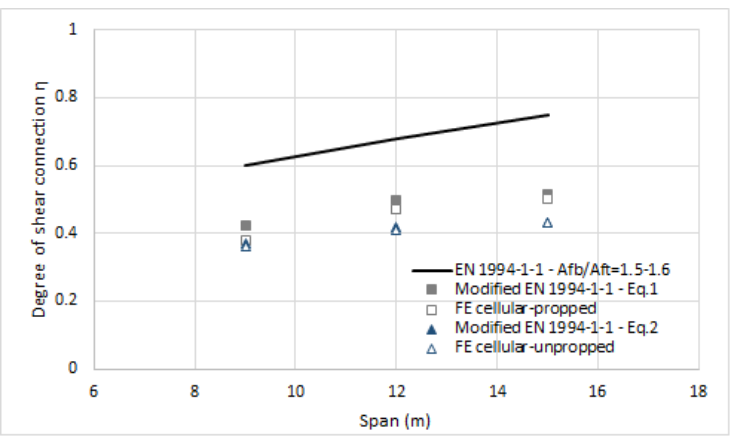

Fig. 7. ANSYS results for cellular beams with flange asymmetry ratio in the range 1.5-1.6.

From the graphical information presented in this paper, it is clear that the proposed modifications to the current EN 1994-1-1 shear connection formulae for propped/unpropped composite beams with regular web openings lead to conservative results that are reasonably accurate. In all cases, the degree of shear connection required by the FE models to reach a moment of $0.95 \mathrm{M}_{\mathrm{pl}}$ and with an end slip below $6 \mathrm{~mm}$ was always smaller than that predicted by Eqs. (1) and (2).

\section{Conclusions}

A series of cases were analysed in order to investigate the minimum degree of shear connection requirements for cellular composite beams and beams that are unpropped during construction.

The minimum degree of shear connection was obtained from FE analyses, based on the assumption that the required degree of shear connection ensures attainment of $0.95 \mathrm{M}_{\mathrm{pl}}$ and the slip in the shear connectors not exceeding the reference value of $6 \mathrm{~mm}$.

By accounting for the presence of regular circular web openings and for the unpropped construction, the new proposed formulae lead to lower values of the minimum degree of shear connection.

For web openings of diameter exceeding $60 \%$ the web depth, the degree of shear connection requirements in the current version of EN 19941-1 for both symmetric and asymmetric steel sections can be relaxed through use of Eq. (1).

For beams that are also unpropped in construction, Eq. (2) can be used, which represents a further reduction in the degree of shear connection.

The proposed relationships were calibrated against parametric FE analyses in Abaqus and ANSYS using models that were previously validated against tests. The degree of shear connection predicted using the proposed relationships was found to be conservative. In most practical cases, additional conservatism is inherently present for cellular composite beams since their design is often governed not only by serviceability criteria but also localised effects around the openings (Vierendeel bending and web post buckling).

\section{References}

[1] Lawson RM and Hicks SJ. Design of composite beams with large web openings. SCI Publication P355, Steel Construction Institute. Ascot; 2011.

[2] European Committee for Standardisation (CEN). EN 1994-1-1, Eurocode 4. Design of composite steel and concrete structures - Part 1-1: General rules and rules for buildings. Brussels; 2004.

[3] Queiroz FD,Vellasco PCGS and Nethercot DA. Finite element modelling of composite beams with full and partial shear connection. Journal of Constructional Steel Research 2007;63(4):505521. 
[4] Development of improved shear connection rules in composite beams (DISCCO). Final report for RFCS project DISCCO, Grant Agreement RFSR-CT-2012-00030. Brussels; 2017.

[5] European Committee for Standardisation (CEN). EN 1992-1-1+A1, Eurocode 2. Design of concrete structures - Part 1-1: General rules and rules for buildings. Brussels; 2014.

[6] Sheehan T, Dai X, Lam D, Aggelopoulos E, Lawson $\mathrm{M}$ and Obiala R. Experimental study on long spanning composite cellular beam under flexure and shear. Journal of Constructional Steel Research 2016;116:40-54.

[7] Aribert J-M. Analyse et formulation pratique de l'influence de la nuance de l'acier du profile sur le degre minimum de connexion partielle d'une poutre mixte. Construction Métallique 1997;3:39-55 (in French). 